\title{
Comparison of simple screening tests for fat malabsorption
}

\author{
P S WEST, G E LEVIN, G E GRIFFIN, J D MAXWELL
}

\begin{abstract}
Three tests were evaluated as screening procedures for fat malabsorption-namely, measurement of serum optical density, serum triglyceride concentration, and ${ }^{14} \mathrm{CO}_{2}$ breath excretion after the administration of a $60 \mathrm{~g}$ fat meal containing $10 \mu \mathrm{Ci}$ glycerol tri[ $\left[1-{ }^{14} \mathrm{C}\right]$ oleate. The results of these tests were compared with fat excreted in a three-day faecal collection after adjustment for completeness of collection as assessed by using nonabsorbable radio-opaque markers. Fifty-two patients with various symptoms and eight normal subjects were studied. The maximum increase in serum optical density or triglyceride concentration above the fasting value discriminated poorly between subjects with normal and increased adjusted faecal fat excretion. In contrast, seven- or eight-hour cumulative ${ }^{14} \mathrm{CO}_{2}$ breath excretion provided good discrimination with only four (7\%) falsepositive and no false-negative results.

The simplicity and convenience of breath analysis make it an attractive alternative to analysis of faecal fat excretion in screening for fat malabsorption.
\end{abstract}

\section{Introduction}

Faecal fat analysis has widely recognised disadvantages including the unpleasantness of stool collection and analysis and uncertainty about the completeness of collection and dietary fat intake. Nevertheless, measuring the fat content of a three- to five-day stool collection remains the standard screening test for fat malabsorption. Alternative screening procedures include oral fat loading with subsequent measurement of serum lipid or absorbance changes ${ }^{12}$ and carbon-14-labelled-triglyceride loading with measurement of breath ${ }^{14} \mathrm{CO}_{2}$ excretion. ${ }^{34}$ Although

Department of Chemical Pathology, St George's Hospital Medical School, London SW17 0RE

P S WEST, MSC, clinical biochemist

G E LEVIN, MSC, MRCPATH, senior lecturer in chemical pathology

Department of Medicine, St George's Hospital Medical School

G E GRIFFIN, PHD, MRCP, lecturer in medicine

J D MAXWELL, MD, FRCP, senior lecturer in medicine each procedure has been claimed to discriminate well between healthy subjects and patients with steatorrhoea, none has gained widespread acceptance.

These tests have not been compared with each other nor have they been evaluated against faecal fat assay using markers to check the completeness of stool collection. Accordingly, we re-evaluated these alternative procedures, comparing ${ }^{14} \mathrm{CO}_{2}$ breath excretion, serum triglyceride concentration, and serum optical density after an oral fat load containing ${ }^{14} \mathrm{C}$ triolein with a three-day faecal fat asssay adjusted for recovery of nonabsorbable markers.

\section{Subjects and methods}

SUBJECTS

Fifty-two unselected subjects (24 men and 28 women) aged 15-81 years (mean 51 years) with various gastrointestinal and non-gastrointestinal symptoms participated in the study. Their body weights ranged from 27 to $110 \mathrm{~kg}$ (mean $61 \mathrm{~kg}$ ). Thirty-nine subjects were admitted for the entire study. Faecal collections were made at home in the remaining 13 subjects. The table shows the various diagnostic categories of the subjects.

Diagnostic grouping of patients in study

\begin{tabular}{|c|c|c|}
\hline Group & Subgroup & $\begin{array}{c}\text { No of } \\
\text { patients }\end{array}$ \\
\hline $\begin{array}{l}\text { Small-bowel disease } \\
\qquad(\mathrm{n}=23)\end{array}$ & $\left\{\begin{array}{l}\text { Coeliac disease (treated) } \\
\text { Coeliac disease (untreated) } \\
\text { Postgastrectomy } \\
\text { Crohn's disease } \\
\text { Duodenal ulcer } \\
\text { Terminal ileal resection } \\
\text { Postvagotomy }\end{array}\right.$ & $\begin{array}{l}7 \\
2 \\
6 \\
3 \\
3 \\
1 \\
1\end{array}$ \\
\hline $\begin{array}{l}\text { Pancreatic disease } \\
\qquad(\mathrm{n}=5)\end{array}$ & $\left\{\begin{array}{l}\text { Previous acute pancreatitis } \\
\text { Chronic pancreatitis } \\
\text { Carcinoma of head of pancreas }\end{array}\right.$ & $\begin{array}{l}2 \\
2 \\
1\end{array}$ \\
\hline $\begin{array}{l}\text { Hepatic disease } \\
\qquad(\mathrm{n}=8)\end{array}$ & $\left\{\begin{array}{l}\text { Alcoholic liver disease } \\
\text { Primary biliary cirrhosis } \\
\text { Secondary biliary cirrhosis } \\
\text { Chronic active hepatitis }\end{array}\right.$ & $\begin{array}{l}4 \\
2 \\
1 \\
1\end{array}$ \\
\hline $\begin{array}{l}\text { Miscellaneous disorders } \\
\qquad(\mathrm{n}=16)\end{array}$ & $\left\{\begin{array}{l}\text { Polycystic kidney disease } \\
\text { Dietary iron deficiency } \\
\text { Folate deficiency (unknown cause) } \\
\text { Growth failure } \\
\text { Respiratory cachexia } \\
\text { Colonic disease } \\
\text { Irritable bowel syndrome }\end{array}\right.$ & $\begin{array}{l}1 \\
1 \\
1 \\
1 \\
1 \\
3 \\
8\end{array}$ \\
\hline
\end{tabular}


Eight healthy laboratory staff (six men and two women) aged 33-54 years (mean 42 years), with body weights from 52 to $79 \mathrm{~kg}$ (mean 68 $\mathrm{kg}$ ) and no gastrointestinal symptoms, were included in the study but did not make faecal collections. Faecal fat values were assumed to be normal.

All subjects gave their informed written consent to the study, which was approved by the hospital ethical committee.

\section{PROTOCOL}

At the start of each study a blood sample was taken from each subject after an overnight fast. Subjects blew into a scintillation phial containing hyamine hydroxide and ethanol, trapping $2 \mathrm{mmol}$ of $\mathrm{CO}_{2}$. They were then given a $60 \mathrm{~g}$ fat meal to which had been added $10 \mu \mathrm{Ci}$ of glycerol tri[1-14 $\mathrm{C}]$ oleate (Radiochemical Centre, Amersham). With the meal subjects were given a slice of toast or gluten-free bread (those with coeliac disease) lightly spread with butter. Blood samples were collected hourly from two to six hours and breath samples hourly from two to nine hours. In nine subjects breath samples were collected for only seven or eight hours. Serum was separated within 30 minutes of collection and stored at $4^{\circ} \mathrm{C}$.

Subjects remained at rest during the test and were allowed one cup of water or black coffee without sucrose every two hours. Eight radioopaque polyethylene pellets (Portex Ltd, Hythe, Kent) were given three times a day with each of the main meals for five days, and from days 3 to 5 faeces were collected. During the five-day period inpatients received a diet containing about $70 \mathrm{~g}$ fat a day, while subjects collecting faeces at home were instructed by the hospital dietitians to prepare food with a fat content of about $70 \mathrm{~g}$ per day.

The fat meal consisted of $100 \mathrm{ml}$ milk (fat content $3.8 \mathrm{~g}$ ); $50 \mathrm{~g}$ fullcream dried milk (fat content $13.2 \mathrm{~g}$ ); $100 \mathrm{~g}$ ice cream (fat content $8.2 \mathrm{~g}$ ); $75 \mathrm{ml}$ double cream (fat content $36 \mathrm{~g}$ ); and $1-2 \mathrm{~g}$ instant coffee powder. The meals were made up in bulk, portioned, and stored at $-20^{\circ} \mathrm{C}$ until use.

\section{METHODS}

Faecal analysis-The weighed stool sample was radiographed and the number of pellets counted. The presence of 72 pellets was taken as $100 \%$ marker recovery. Faecal fat was estimated in the stool ${ }^{5}$ and the result adjusted for marker recovery. ${ }^{6}$

Serum optical density was measured within seven hours of collection and the maximum increase recorded at room temperature with a Perkin Elmer spectrophotometer at $620 \mathrm{~nm}$ using the fasting sample as blank.

Serum triglyceride concentrations were measured within four days of collection using an LKB reaction rate analyser. ${ }^{7}$ The maximum increase in triglyceride concentration above the fasting sample was recorded.

Breath ${ }^{14} \mathrm{CO}_{2}$ activity was measured in the hourly samples by liquid scintillation counting (Nuclear Enterprises, Edinburgh) and compared with a standard obtained by diluting the stock ${ }^{14} \mathrm{C}$-triolein. Breath samples and the standard were counted under identical conditions. The hourly values were expressed ${ }^{3}$ as a percentage of the total radioactivity ingested per $\mathrm{mmol} \mathrm{CO}_{2} \times 10^{4}$. Cumulative hourly values from zero to nine hours were recorded.

\section{Results}

Marker recovery-The mean faecal pellet recovery was $74 \%$ in subjects with an abnormal adjusted faecal fat excretion (range 14$112 \%$ ) and $93 \%$ in subjects with normal adjusted faecal fat values (range $22-125 \%$ ). Figure 1 shows the distribution of values.

Mean faecal weight for the three-day collection was $595 \mathrm{~g}$ in those with an abnormal adjusted faecal fat excretion (range 70-2090 g) and $445 \mathrm{~g}$ in those with a normal adjusted value (range 95-1500 g). Figure 1 shows the distribution of values.

Faecal fat-Figure 2 shows adjusted faecal fat values. Abnormal values (defined as greater than $18 \mathrm{mmol} / 24 \mathrm{~h}(5 \mathrm{~g} / 24 \mathrm{~h})$ ) were detected in 32 subjects $(62 \%)$. In seven subjects $(13 \%)$ faecal fat excretion was normal but became abnormal after adjustment for marker recovery. In subjects with increased faecal fat excretion, values after adjustment always lay outside the normal range.

Serum optical density-Peak values occurred within the six-hour period of measurement in 55 subjects $(92 \%)$. Peak optical density was $0.75 \pm 0.31$ (mean $\pm S D$ ) in subjects with a normal adjusted faecal fat excretion but $0.52 \pm 0.32$ in those with an abnormal adjusted faecal fat excretion. This difference in mean values was significant $(p<0.01)$, but discrimination between the two groups was nevertheless poor (fig 2).

Serum triglyceride concentrations-Peak values were observed within the six-hour period of measurement in 52 subjects $(87 \%)$. The peak concentration was $1.66 \pm 1.06 \mathrm{mmol} / \mathrm{l}(147 \pm 94 \mathrm{mg} / 100 \mathrm{ml})$ in subjects with normal adjusted faecal fat excretions but $0.98 \pm 0.74$ $\mathrm{mmol} / \mathrm{l}(87.66 \mathrm{mg} / 100 \mathrm{ml})$ in subjects with abnormal adjusted faecal fat excretions. This difference in mean values was significant $\mathbb{D}$ $(p<0.01)$, but discrimination between the two groups was again poor (fig 2). The correlation between peak triglyceride concentration and peak absorbance was good $(r=0 \cdot 78, p<0.01)$.

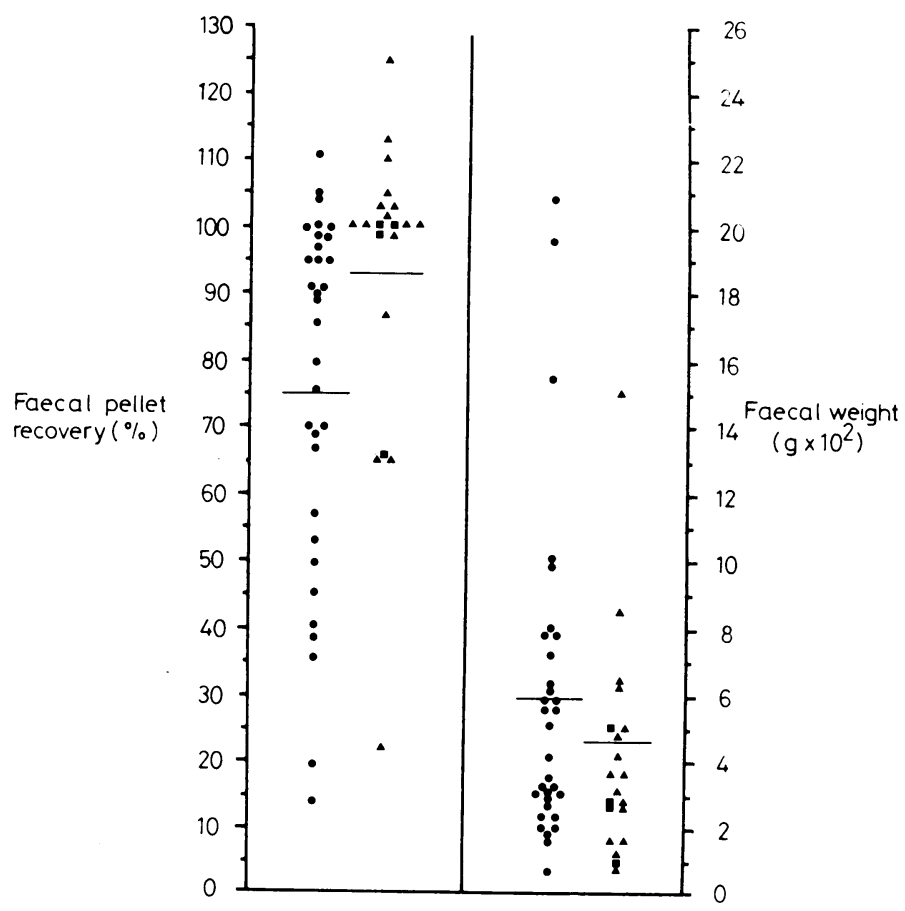

FIG 1-Recovery of faecal pellets and distribution of faecal weight based on three-day faecal collection. Horizontal lines indicate mean values.

- Subjects with abnormal adjusted faecal fat excretion. $\boldsymbol{\Delta}=$ Subjects with normal adjusted faecal fat excretion. $\mathbf{m}=$ Subjects with normal adjusted faecal fat excretion and abnormal cumulative seven-hour excretion of ${ }^{14} \mathrm{CO}_{2}$.

Breath ${ }^{14} \mathrm{CO}_{2}$ activity is usually expressed as peak percentage ${ }^{14} \mathrm{CO}$, excretion per mmol $\mathrm{CO}_{2} \cdot{ }^{3}$ In the present study peak values were achieved in only 15 subjects $(25 \%)$ by seven hours and in $25(42 \%)$ by nine hours. Figure 3 gives the cumulative excretion of ${ }^{14} \mathrm{CO}_{2}$ at six, seven, eight, and nine hours and shows that discrimination between subjects with normal and abnormal adjusted faecal fat excretions was good at seven and eight hours but less accurate at six and nine hours. The cumulative seven-hour breath ${ }^{11} \mathrm{CO}_{2}$ expressed as the percentage triolein dose $\times 10^{4}$ was used in subsequent expressions of the ${ }^{14} \mathrm{CO}_{2}$ data. The lower limit of normal was taken as $185 \times 10^{-4 \%}$. No falsenegative results were obtained, but four of the 60 subjects yielded false-positive values with respect to adjusted faecal fat values. One subject had coeliac disease, was receiving a gluten-free diet, and did not have diarrhoea. The second subject had macrocytic anaemia due to folate deficiency, and a repeat breath test confirmed the original low value; further investigation was refused by the patient. The third patient had inflammatory bowel disease; results of liver function tests were abnormal, and a liver biopsy specimen showed severe fatty changes. The fourth patient was diagnosed as having the irritable bowel syndrome, and a repeat breath test confirmed the original low value.

\section{Discussion}

The results we obtained using ${ }^{14} \mathrm{C}$-triolein showed good discrimination between subjects with and without steatorrhoea as assessed by faecal fat analysis. In contrast, the discrimination 
FIG 2-Cumulative seven-hour excretion of ${ }^{14} \mathrm{CO}_{2}$, peak optical density, peak triglyceride concentration, and unadjusted and adjusted faecal fat excretions in all subjects. (Symbols as in figure 1.)

Conversion: SI to traditional unitsTriglyceride: $1 \mathrm{mmol} / 1 \approx 88.6 \mathrm{mg} / 100 \mathrm{ml}$. Faecal fat: $1 \mathrm{mmol} / 24 \mathrm{~h} \approx 28.4 \mathrm{mg} / 24 \mathrm{~h}$.

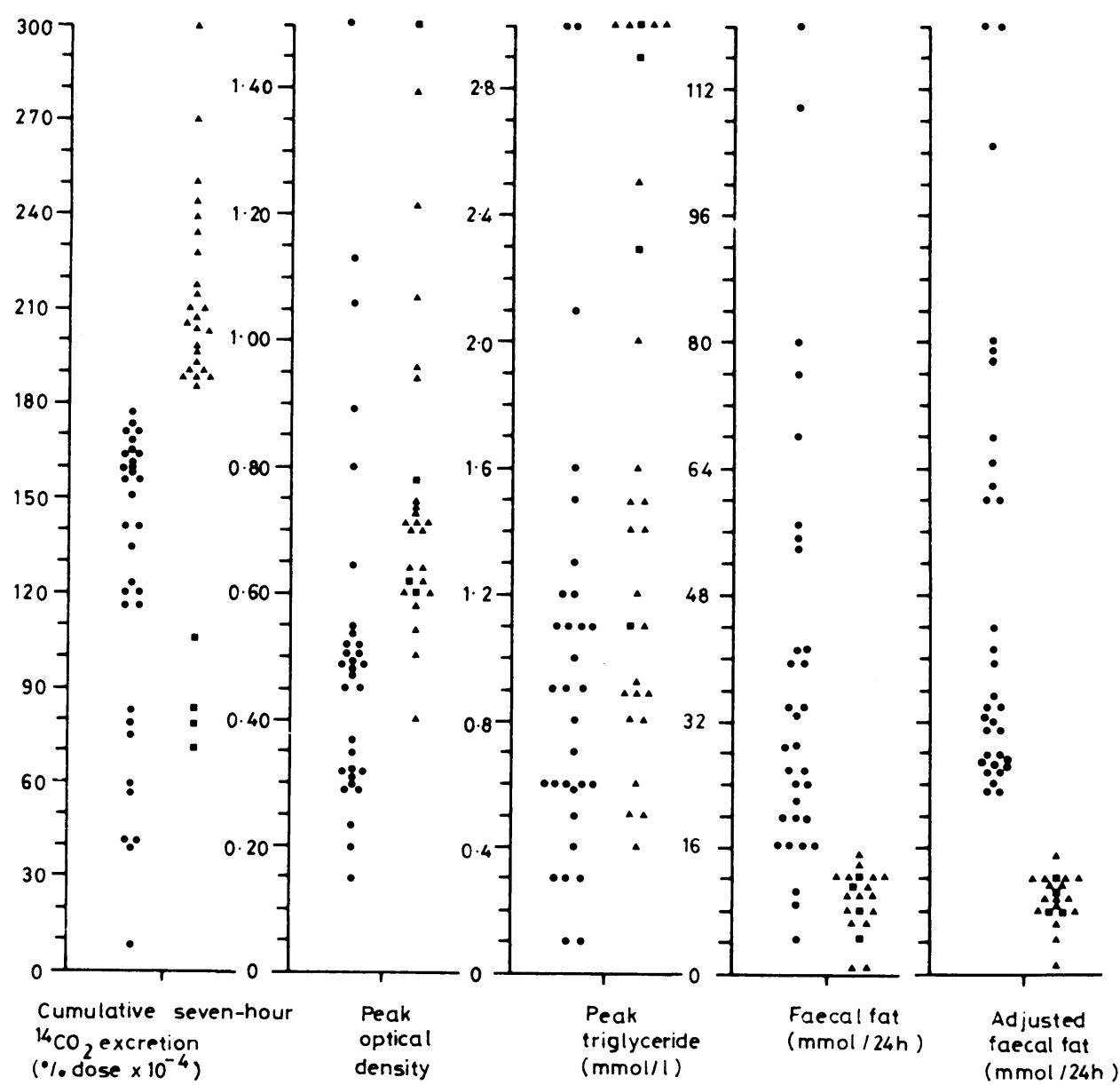

obtained with serum triglyceride concentrations or absorbance measurements was considerably poorer.

Several groups have used oral fat tolerance tests to screen for steatorrhoea in adults. Most workers use butter with toast to provide the fat load, given either as a fixed quantity of lipid ${ }^{1}{ }^{8}$ or as 0.5 or $1.0 \mathrm{~g} / \mathrm{kg}$ body weight. ${ }^{2}{ }^{9}$ Plasma lipid changes are usually measured by spectrophotometry or nephelometry. These tests have been claimed to discriminate well between subjects with and without fat malabsorption. In our experience (fig 2), however, the poor discrimination obtained with serum triglyceride concentrations or absorbance measurements invalidates their use as screening tests, although the conditions of testing differed from those used by other authors.

Most workers assessing ${ }^{14} \mathrm{CO}_{2}$ breath tests have used ${ }^{14} \mathrm{C}$ glyceryl tripalmitate and in general claimed good discrimination between healthy subjects and patients with steatorrhoea. ${ }^{3}$ 410-13 These workers gave the ${ }^{14} \mathrm{C}$-triglyceride with corn oil as either $1 \mathrm{~g} / \mathrm{kg}$ body weight ${ }^{310-12}$ or $25 \mathrm{~g}$ per subject.4 ${ }^{13}$ By contrast two groups, one using a $12.5 \mathrm{~g}$ fat load of sour cream $^{14}$ and a second $25 \mathrm{~g}$ corn oil $^{15}$ but otherwise a similar technique, found poor discrimination.

The first use of ${ }^{14} \mathrm{C}$-triolein was reported in 1966 but in only a few patients. ${ }^{16}$ Newcomer et $a l^{4}$ compared ${ }^{14} \mathrm{CO}_{2}$ breath excretion after $5 \mu \mathrm{Ci}$ triolein and $5 \mu \mathrm{Ci}$ tripalmitin given sequentially to the same subjects together with $25 \mathrm{~g}$ corn oil. In their larger study they claimed good discrimination between healthy subjects and those with steatorrhoea with both triglycerides, although ${ }^{14} \mathrm{C}$-triolein was superior.

We chose a $60 \mathrm{~g}$ fat meal rather than a smaller fat load to increase the rise in maximum serum absorbance and triglyceride values. Differences in the timing of peak ${ }^{14} \mathrm{CO}_{2}$ excretion noted between this and previous studies probably relate to variations in the amount and composition of the inert fat load or in the
FIG 3-Cumulative six-, seven-, eight-, and nine-hour excretion of ${ }^{14} \mathrm{CO}_{2}$ in all subjects. (Symbols as in figure 1.) 
rate of gastric emptying. Increasing the corn-oil load from 25 to $50 \mathrm{~g}$ delays excretion of ${ }^{14} \mathrm{CO}_{2}$ from ingested ${ }^{14} \mathrm{C}$-triolein by several hours.

Attempts to increase the discriminatory power of breath tests by adjusting ${ }^{14} \mathrm{CO}_{2}$ excretion for body weight (PSW et al, unpublished observations) and basal metabolic rate ${ }^{17}$ have not proved successful. Obese subjects (body weight $25 \%$ in excess of standard weight), however, have reduced ${ }^{14} \mathrm{CO}_{2}$ excretion after ${ }^{14} \mathrm{C}$-tripalmitin. ${ }^{10}$ By contrast, ${ }^{14} \mathrm{CO}_{2}$ excretion is enhanced in diabetes mellitus. ${ }^{15}$ The interpretation of the test may be in doubt in these disorders and in others affecting the distribution or metabolism of ${ }^{14} \mathrm{C}$-triglyceride such as thyrotoxicosis, chronic respiratory disorders, and parenchymatous liver diseases, but evaluation remains to be carried out.

Non-absorbable radio-opaque pellets are simple and convenient to use and correlate closely with polyethylene glycol and chromic oxide as continuous faecal markers. ${ }^{6}$ Our finding of seven subjects in whom the breath-test values became consistent with the adjusted faecal fat excretion suggests that using markers is important in such evaluations. Nevertheless, in one subject with an obstructing carcinoma of the colon who was not included in the study no pellets were recovered despite passage of stool. Plain abdominal $x$-ray examination showed retention of all the pellets proximal to the obstructing lesion.

We conclude that measuring either maximal triglyceride concentration or absorbance after a $60 \mathrm{~g}$ fat meal does not discriminate satisfactorily between subjects with and without increased faecal fat excretion. Cumulative ${ }^{14} \mathrm{CO}_{2}$ breath excretion after ingestion of $10 \mu \mathrm{Ci}{ }^{14} \mathrm{C}$-triolein (administered with the fat meal), however, provided good discrimination with no falsenegative and only four apparent false-positive results.

${ }^{14} \mathrm{CO}_{2}$ breath testing is simple to perform, reliable, and acceptable to patients and staff. These advantages make it an attractive alternative to stool collection in screening for fat malabsorption. While it may be premature to suggest that breath testing might replace faecal fat analysis completely, our results suggest that the finding of normal ${ }^{14} \mathrm{CO}_{2}$ breath excretion is good evidence of normal fat absorption. Under these circumstances stool collection may be avoided.

We thank Miss Sally Day, chief dietitian at St George's Hospital, and her staff for preparing the fat meal and diets, Miss Moira Kirk for radiographing the stool specimens, and Mrs Jean Sterling for secretarial help.
We acknowledge the financial help of the medical research committee, St George's Hospital.

\section{References}

${ }^{1}$ Penfold WA, Keynes WM. Use of a standard fatty meal as a test of fat absorption. Ann Surg 1971;173:157-63.

Bentley SJ, Eastham RD, Lane RF. Oral butter fat test meal with serum nephelometry in suspected fat malabsorption. F Clin Pathol $1975 ; 28$ : 80-1.

${ }^{3}$ Kaihara S, Wagner HN. Measurement of intestinal fat absorption witho carbon-14 labelled tracers. F Lab Clin Med 1968;71:400-11.

4 Newcomer AD, Hofmann AF, DiMagno EP, Thomas PJ, Carlson GI. Triolein breath test. A sensitive and specific test for fat malabsorption. Gastroenterology $1979 ; 76: 6-13$.

${ }^{5}$ Van de Kamer JH, Huinink HtB, Weyers HA. Rapid method for the determination of fat in faeces. $\mathcal{F}$ Biol Chem 1949;177:347-55.

${ }^{6}$ Simpson FG, Hall GP, Kelleher J, Losowsky MS. Radio-opaque pellets $\overparen{D}$ as faecal markers for faecal fat estimation in malabsorption. Gut 1979 ; $20: 581-4$.

Bergmeyer H. Triglycerides: determination after enzymatic hydrolysis In: Bergmeyer H, ed. Methods of enzymatic analysis. Vol 4. New York. and London: Academic Press, 1971:1831-4.

${ }^{8}$ Gardner FH, Santiago EP. Oral absorption tolerance tests in tropical $\vec{\omega}$ sprue. AMA Archives of Internal Medicine 1956;98:467-74.

${ }^{9}$ Osmon KL, Zinn WJ, Wharton GK. Simplified test of fat malabsorption. Comparison of serum turbidity, chylomicronemia and total lipid values after fat test meal. $\mathcal{F} A M A 1957 ; \mathbf{1 6 4}: 633-8$.

${ }^{10}$ Bhatia SK, Bell TK, Love AHG, Montgomery DAD. An evaluation of a test using ${ }^{14} \mathrm{C}$ labelled triglyceride in the diagnosis of steatorrhoea. N Ir $\mathcal{F}$ Med Sci $1969 ; 2: 545-52$.

${ }^{11}$ Burrows PJ, Fleming JS, Garrett ES, Ackery DM, Colin-Jones DG, Bamforth J. Clinical evaluation of the ${ }^{14} \mathrm{C}$ fat absorption test. Gut $1974 ; \mathrm{O}$ $15: 147-50$.

${ }^{12}$ Mills PR, Horton PW, Watkinson G. Breath tests for the detection of fat음 malabsorption. Scott Med f 1979;24:324-5.

${ }^{13}$ Chen IW, Azmudeh K, Connell AM, Saenger EI. ${ }^{14} \mathrm{C}$ tripalmitin breath test as a diagnostic aid for fat malabsorption due to pancreatic insufficiency. F Nucl Med 1974;15:1125-9.

${ }^{14}$ Levy-Gigi C, Mandelowitz N, Peled Y, Ayalon D, Gilat T. Is the fat $\overrightarrow{C O}$ breath test effective in the diagnosis of fat malabsorption and pancreatic disease? Digestion 1978;18:77-85.

15 Caspary WF. Breath tests. Clin Gastroenterol 1978;7:351-74.

16 Abt AF, Von Schuching SL. Fat utilisation test in disorders of fat metabolism. Bulletin of the fohns Hopkins Hospital 1966;119:316-36.

17 Strange RC, Reid J, Holton D, Jewell NP, Percy-Robb IW. The glyceryl ${ }^{14} \mathrm{C}$ tripalmitate breath test: a reassessment. Clin Chim Acta 1980;103: 317-23.

(Accepted 19 March 1981)

,

